\title{
Early summer southern China rainfall variability and its oceanic drivers
}

\author{
Weijing $\mathrm{Li}^{1,2} \cdot$ Hong-Chang Ren ${ }^{1,3} \cdot$ Jinqing Zuo ${ }^{1,2} \cdot$ Hong-Li Ren ${ }^{2}$
}

Received: 17 February 2017 / Accepted: 5 September 2017 / Published online: 21 September 2017

(C) The Author(s) 2017. This article is an open access publication

\begin{abstract}
Rainfall in southern China reaches its annual peak in early summer (May-June) with strong interannual variability. Using a combination of observational analysis and numerical modeling, the present study investigates the leading modes of this variability and its dynamic drivers. A zonal dipole pattern termed the southern China Dipole (SCD) is found to be the dominant feature in early summer during 1979-2014, and is closely related to a low-level anomalous anticyclone over the Philippine Sea (PSAC) and a Eurasian wave-train pattern over the mid-high latitudes. Linear regressions based on observations and numerical experiments using the CAM5 model suggest that the associated atmospheric circulation anomalies in early summer are linked to decaying El Niño-Southern Oscillation-like sea surface temperature (SST) anomalies in the tropical Pacific, basin-scale SST anomalies in the tropical Indian Ocean, and meridional tripole-like SST anomalies in the North Atlantic in the previous winter to early summer. The tropical Pacific and Indian Ocean SST anomalies primarily exert an impact on the SCD through changing the polarity of the PSAC, while the North Atlantic tripole-like SST anomalies mainly
\end{abstract}

Electronic supplementary material The online version of this article (doi:10.1007/s00382-017-3898-0) contains supplementary material, which is available to authorized users.

Hong-Chang Ren

renhongchang921@sina.com

1 Collaborative Innovation Center on Forecast and Evaluation of Meteorological Disasters, Nanjing University of Information Science and Technology, Nanjing, China

2 Laboratory for Climate Studies, National Climate Center, China Meteorological Administration, Beijing 100081, China

3 National Meteorological Center, China Meteorological Administration, Beijing 100081, China exert a downstream impact on the SCD by inducing a Eurasian wave-train pattern. The North Atlantic tripole-like SST anomalies also make a relatively weak contribution to the variations of the PSAC and SCD through a subtropical teleconnection. Modeling results indicate that the three-basin combined forcing has a greater impact on the SCD and associated circulation anomalies than the individual influence from any single oceanic basin.

Keywords Rainfall variability $\cdot$ South China $\cdot$ SST anomalies $\cdot$ Teleconnections

\section{Introduction}

The East Asian summer monsoon plays a dominant role in setting rainfall variability over China in summer (Ding and Chan 2005). The rain band moves from low to mid-high latitudes as the summer monsoon advances northward from early to late summer. However, migration of the rain band is not gradual; it usually jumps from one relatively stationary stage to another (Wang et al. 2009; Su et al. 2014). In May-June, the rain band is located mainly in southern China, but in July it abruptly shifts northward to the Yangtze valley.

In the past few decades, a significant amount of effort has been devoted to understanding the physical processes and mechanisms governing the summer monsoon and rainfall variability over East Asia (e.g. Lau 1992; Simmonds et al. 1999; Zhang 2001; Zhou and Yu 2005). Most studies treat the summer season as the June-July-August mean. In fact, over South China there are distinct differences in the mean state, rainfall variability, and associated atmospheric circulation patterns between early and late summer (Chang et al. 2000; Wang et al. 2009; Su et al. 2014). Their controlling 
mechanisms may also be different. Early summer rainfall anomalies in southern China are frontal and monsoonal (Chen et al. 2001; Zheng et al. 2006), while late summer rainfall comes mainly from tropical cyclones as the western Pacific subtropical high (WPSH) shifts northward (Ren et al. 2002; Lee et al. 2010).

Recent studies have examined the variability and predictability of East Asian rainfall in early summer. Ye and $\mathrm{Lu}$ (2011) investigated the sub-seasonal differences in ENSOrelated rainfall anomalies over East Asia, revealing more (less) rainfall anomalies in early (late) summer in southern China during the decaying phase of El Niño. Mao et al. (2011) examined the general atmospheric circulation anomalies associated with the interannual variations in early summer rainfall in southern China. Yim et al. (2014) analyzed the southeast China rainfall predictability in early summer and established a physical-empirical model based on sea surface temperature (SST) tendency in the previous winter and spring. However, the associated physical mechanisms linking early summer rainfall anomalies in southern China to SST anomalies remain poorly understood.

This study aims to identify the leading mode of rainfall anomalies in southern China and the associated atmospheric circulation patterns in early summer. More importantly, we will investigate the linkage between southern China rainfall anomalies in early summer and SST anomalies in the previous winter and spring, and the physical mechanisms responsible, using observations and numerical simulations.

The remainder of this manuscript is organized as follows. Section 2 describes the datasets, model, and experiments used in this study. Section 3 presents the dominant modes of southern China rainfall anomalies and associated atmospheric circulation characteristics in May-June. Section 4 explores the linkage of southern China rainfall anomalies in early summer to SST anomalies in the previous winter and spring, as well as the physical mechanisms responsible for the linkage, and corresponding model simulations are presented in Sect. 5. Finally, Sect. 6 provides a discussion and summary.

\section{Data, model, and experiments}

\subsection{Observational data and method}

The precipitation data for the period 1979-2014 used in this study are derived from 54 meteorological stations that are well distributed throughout southern China. These datasets are provided by the National Climate Center of the China Meteorological Administration. The monthly atmospheric circulation data are obtained from the recently released ERA-Interim dataset (Dee et al. 2011) of the European Centre for Medium-Range Weather Forecasts (ECMWF) for the years 1979-2014, with a horizontal resolution of $1.5^{\circ} \times 1.5^{\circ}$. SST data are obtained from the Hadley Centre Sea Ice and Sea Surface Temperature (HadISST) dataset for the years 1979-2014, with a horizontal resolution of $1^{\circ} \times 1^{\circ}$ (Rayner et al. 2003).

The Niño3.4 and the tropical Indian Ocean (TIO) SST indices used in this study are defined as the regionally averaged SST anomalies over $5^{\circ} \mathrm{S}-5^{\circ} \mathrm{N}, 170^{\circ}-120^{\circ} \mathrm{W}$ and $15^{\circ} \mathrm{S}-15^{\circ} \mathrm{N}, 40^{\circ} \mathrm{E}-100^{\circ} \mathrm{E}$, respectively. The North Atlantic tripole (NAT) SST index is constructed as the sum of regionally averaged SST anomalies in the tropics $\left(5^{\circ}-20^{\circ} \mathrm{N}, 60^{\circ}-20^{\circ} \mathrm{W}\right)$ and in the subpolar ocean $\left(40^{\circ}-55^{\circ} \mathrm{N}\right.$, $55^{\circ}-30^{\circ} \mathrm{W}$ ) minus the regionally averaged SST anomalies in the middle North Atlantic $\left(25^{\circ}-35^{\circ} \mathrm{N}, 80^{\circ}-50^{\circ} \mathrm{W}\right)$. The Philippine Sea anomalous anticyclone (PSAC) index is defined as the sea level pressure anomaly averaged over the Philippine Sea $\left(10^{\circ}-20^{\circ} \mathrm{N}, 120^{\circ}-150^{\circ} \mathrm{E}\right)$ following Wang et al. (2000). The intensity of the WPSH is defined following Liu et al. (2012) and is provided by the National Climate Center of the China Meteorological Administration.

To remove the impact of ENSO on atmospheric circulation, linear regression patterns of circulation anomalies against the winter Niño3.4 index are calculated, and these patterns are removed from the original circulation fields. Then the regression and correlations against other indices are recalculated using the new circulation fields. The statistical significance of the regression and correlation is determined by a two-tailed Student's $t$ test.

Seasons in this work are defined as winter (December-January-February mean; DJF), spring (March-April mean; MA) and early summer (May-June mean; MJ).

\subsection{Model and experimental setup}

The atmospheric general circulation model (AGCM) used is the Community Atmospheric Model (CAM version 5.3) developed by the National Center for Atmospheric Research (NCAR).CAM is coupled to the Community Land Model (CLM version 4.0), and a version with $1.9^{\circ}$ latitude by $2.5^{\circ}$ longitude resolution with 30 vertical levels is used in this study.

Four sensitivity experiments are conducted to assess the contribution of SST anomalies in the tropical Pacific Ocean (TPO run), tropical Indian Ocean (TIO run), North Atlantic (NAT run), and the contribution of SST anomalies in all three oceanic basins (PIA run), respectively. A 10-year spin-up is run before conducting the sensitivity experiments, and integrations of 7 months (from December to June) are conducted for all experiments. Each experiment consists of 30 ensemble members with slightly varying atmospheric initial conditions, and the ensemble mean of the 30 members is used for analysis. In the control run, the model is forced with a prescribed monthly climatology of SST and sea ice 
that is obtained from the monthly HadISST dataset for the period 1981-2010.

\section{Leading modes of rainfall anomalies and associated circulation characteristics}

\subsection{Leading modes of interannual variability}

Empirical orthogonal function (EOF) analysis of the MJ mean rainfall anomalies during 1979-2014 was performed in southern China $\left(95^{\circ}-125^{\circ} \mathrm{E}, 20^{\circ}-30^{\circ} \mathrm{N}\right)$, and Fig. 1 shows the spatial patterns of the first two leading EOF modes and time series of the corresponding principal components (PC). The first leading EOF mode explains about $19 \%$ of the total variance and is well distinguished from the second mode according to the rule of North et al. (1982). This EOF mode features a zonal dipole pattern in rainfall anomalies over southern China (the southern China rainfall dipole; SCD) (Fig. 1a). The positive phase of the SCD is characterized by increased (decreased) rainfall anomalies in southeast (southwest) China, and vice versa.

An SCD index that represents variations of the southern China rainfall dipole is constructed as the difference in normalized rainfall anomalies between southeast China (blue dots in Fig. 1a) and southwest China (red dots in Fig. 1a). The SCD index is highly correlated with the first PC (PC1) of southern China rainfall anomalies in MJ during 1979-2014 (Fig. 1c). Their correlation coefficient $(R)$ is about 0.83 , which is statistically significant at the $99 \%$ confidence level. This suggests that the SCD is most likely a physical mode in early summer.

We present the second leading EOF mode of MJ anomalies in southern China in Fig. $1 \mathrm{~b}$ and the corresponding PC time series in Fig. 1d. This mode is characterized by a north-south dipole in rainfall anomalies over southern China, but it explains only about $10 \%$ of the total variance. Therefore, this study mainly focuses on the atmospheric circulation and SST anomalies associated with the MJ SCD and the physical mechanisms involved. We show observed results associated with the SCD index in the following sections, but similar results can also been obtained from those associated with the PC1 of southern China rainfall anomalies (Figures not shown).
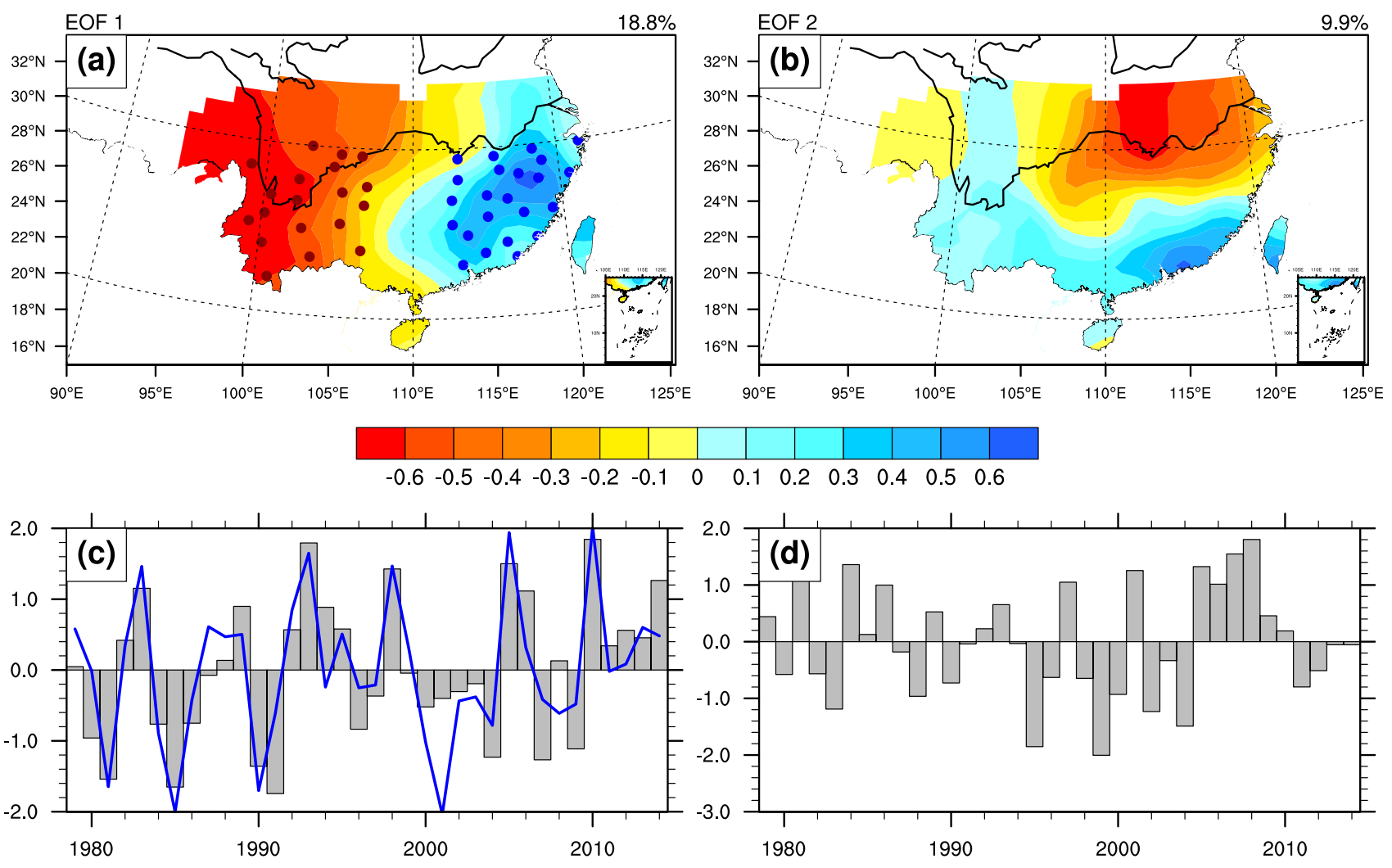

Fig. 1 The first two leading modes of MJ rainfall anomalies in southern China for the period 1979-2014. The spatial patterns show the rainfall anomalies regressed against a PC1 and b PC2, and the corre-

sponding PCs are shown in $\mathbf{c}$ and $\mathbf{d}$. Dots in a represent stations used to define the SCD index, and the blue line in $\mathbf{c}$ is the time series of the SCD index 


\subsection{Associated atmospheric circulation anomalies}

To reveal the relationship between the SCD and atmospheric circulation anomalies, Fig. 2 shows the spatial distribution of atmospheric circulation anomalies regressed against the SCD index in MJ during 1979-2014. High values of the SCD index tend to correspond to significant and positive geopotential height anomalies over the western Pacific at $500 \mathrm{hPa}$ (Fig. 2b), indicating an enhancement and westward movement of the WPSH, corresponding to an anomalous PSAC at $850 \mathrm{hPa}$ (Fig. 2c). These circulation anomalies favor increased (decreased) rainfall in southeast (southwest)
China. This finding is supported by the results shown in Fig. 3, which indicate that the intensified PSAC favors the convergence (divergence) of water vapor anomalies in southeast (southwest) China; the converse is also true.

Figure 4a shows time series of the SCD, WPSH, and PSAC indices in MJ during 1979-2014. The correlation coefficient between the SCD and WPSH (PSAC) indices reaches 0.53 (0.66), both statistically significant at the $99 \%$ confidence level. This confirms that the SCD is closely related to the WPSH and PSAC in MJ. In addition, there are easterly wind anomalies at lower levels over north India (Fig. 2c), which limit water vapor transport from the tropical
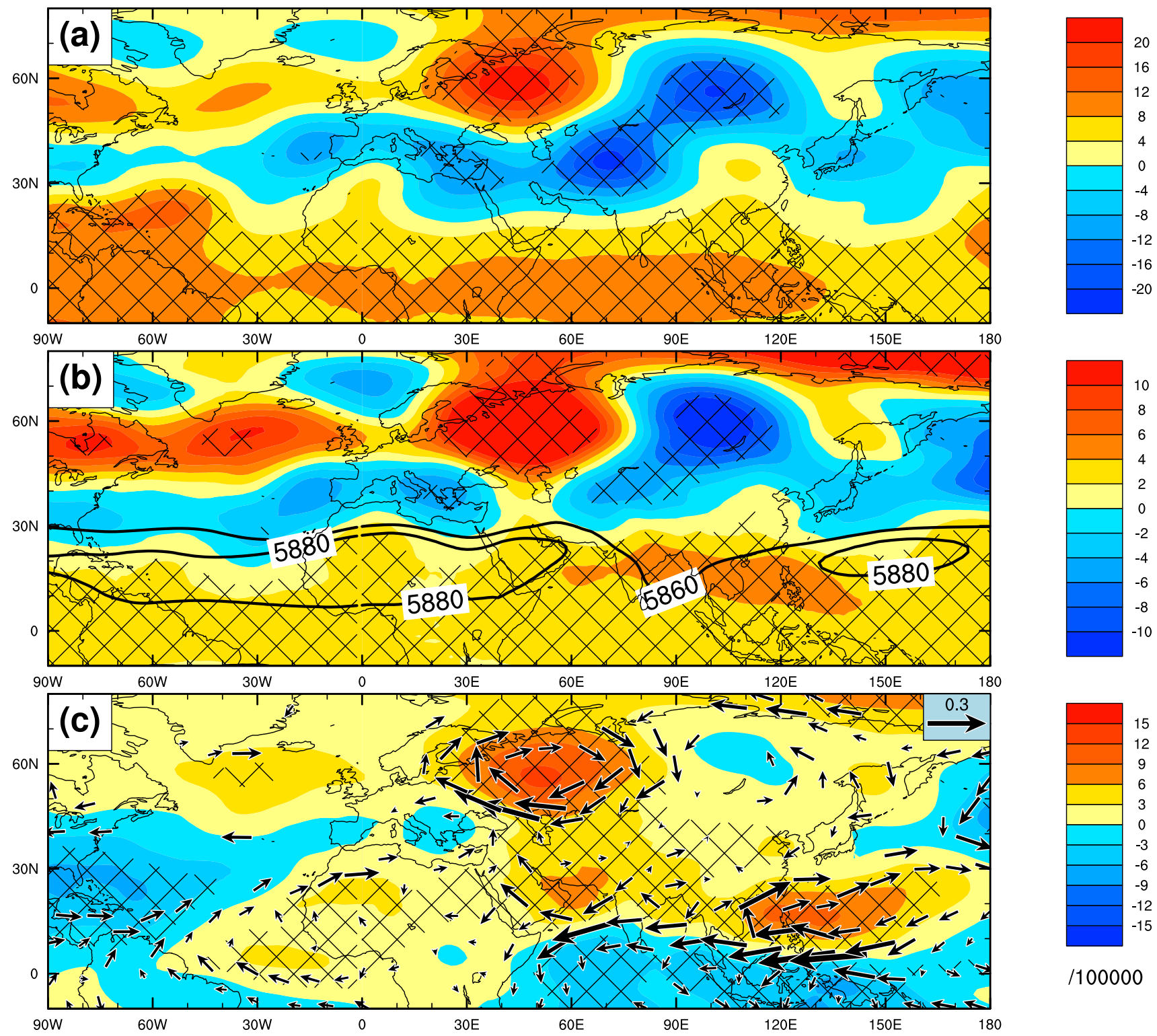

$/ 100000$

Fig. 2 Regressions against the SCD index in MJ of geopotential height anomalies (shading; gpm) at a $200 \mathrm{hPa}$ and b $500 \mathrm{hPa}$. c Same as $\mathbf{a}$, but for the stream function (shading; $10^{5} \mathrm{~m}^{2} \mathrm{~s}^{-1}$ ) and wind vec- tor (vectors; $\mathrm{m} \mathrm{s}^{-1}$ ) anomalies at $850 \mathrm{hPa}$. Black contours in $\mathbf{b}$ denote the climatological mean of the 500-hPa geopotential height (gpm). Cross-hatching denotes significance at the $95 \%$ confidence level 


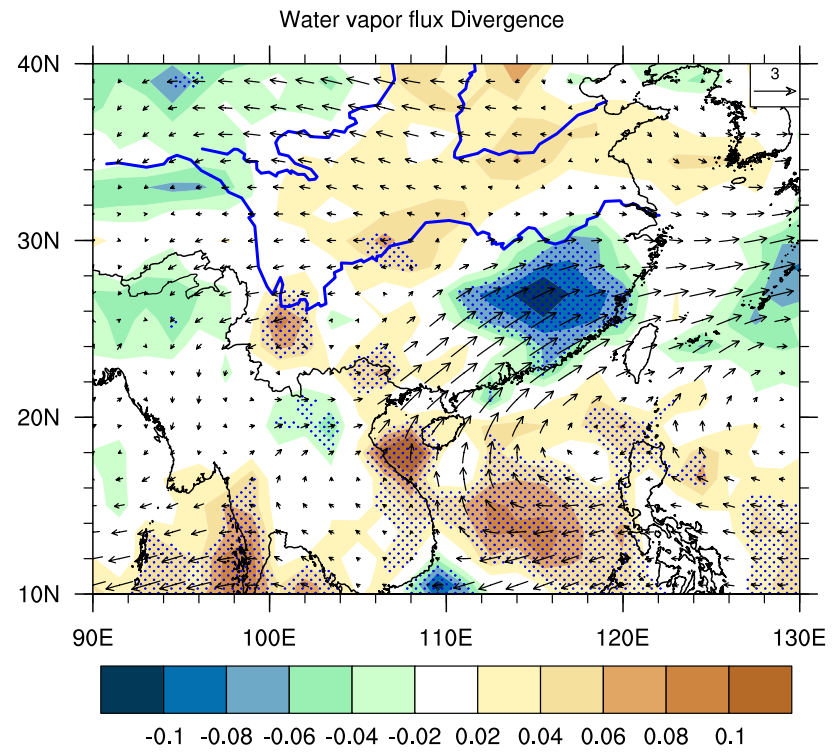

Fig. 3 Regression of vertically integrated (from the surface to $300 \mathrm{hPa}$ ) water vapor transport anomalies (vector; $\mathrm{kg} \mathrm{m}^{-1} \mathrm{~s}^{-1}$ ) against the PSAC index and corresponding divergence (shading; dots indicate significance at the $90 \%$ confidence level) in MJ
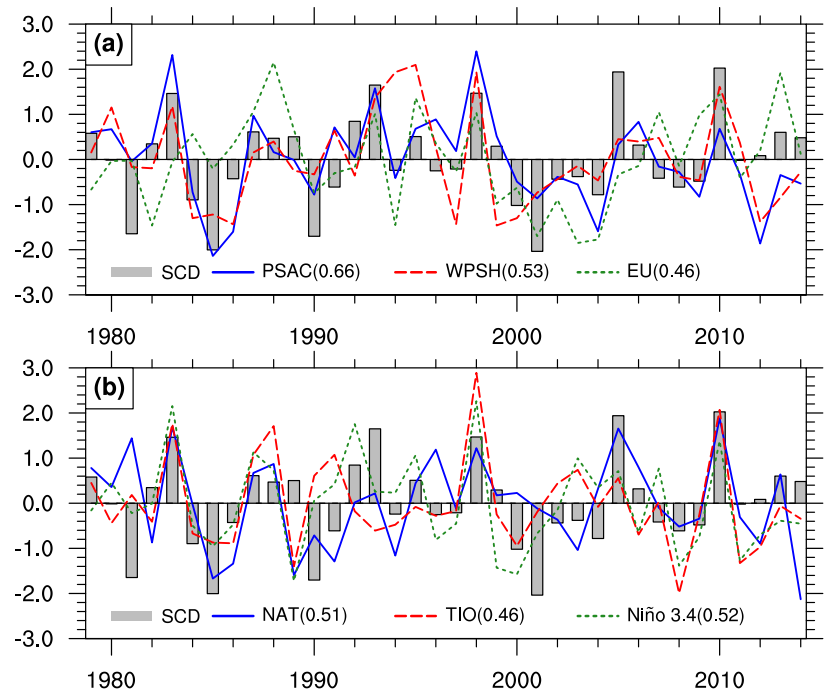

Fig. 4 a Time series of the normalized SCD index (bars), PSAC index (blue line), WPSH index (dashed red line), and EU index (dotted green line) in MJ, and $\mathbf{b}$ time series of the normalized SCD index (bars) in MJ, NAT index (blue line) in MA, TIO index (dashed red line) in MA, and Niño 3.4 index (dotted green line) in DJF for the period 1979-2014. Numbers in brackets denote the correlation coefficient between the SCD and corresponding indices

ocean to southwest China and thus lead to less rainfall in this region.

Another notable feature of the 500-hPa geopotential height anomalies is a wave-train pattern spanning mid- to high-latitude Eurasia (Fig. 2b). When the SCD is in its positive phase, there are positive geopotential height anomalies over Europe and the Okhotsk Sea, but negative geopotential height anomalies over Siberia, and vice versa for the negative phase. This wave-train pattern shows the same phase in the lower, middle, and upper troposphere, thereby exhibiting an equivalent barotropic structure (Fig. 2). Since such a wave-train pattern over Eurasia resembles the typical Eurasian teleconnection pattern (Wallace and Gutzler 1981), except for some differences in the center positions of the pattern, a modified Eurasia pattern (EU) index is defined as

$$
\begin{aligned}
& {\left[\overline{\mathrm{H} 500}_{\left(55^{\circ}-75^{\circ} \mathrm{N}, 20^{\circ}-60^{\circ} \mathrm{E}\right)}-2 \times \overline{\mathrm{H} 500}_{\left(55^{\circ}-65^{\circ} \mathrm{N}, 80^{\circ}-120^{\circ} \mathrm{E}\right)}\right.} \\
& \left.+\overline{\mathrm{H} 500}_{\left(50^{\circ}-60^{\circ} \mathrm{N}, 130^{\circ}-150^{\circ} \mathrm{E}\right)}\right] / 4,
\end{aligned}
$$

where $\mathrm{H} 500$ represents the geopotential height at $500 \mathrm{hPa}$. Figure 4a shows that the SCD index and the modified EU index are highly in-phase in MJ during 1979-2014. Their correlation coefficient reaches 0.46 , which is significant at the $99 \%$ confidence level. As revealed in the previous studies, the positive phase of the EU pattern is generally concurrent with strengthened blocking highs over mid- to high-latitude Eurasia, which favors a strengthened East Asian subtropical front and thus more rainfall anomalies in southeast China during summer (Zhang and Tao 1998; Li and Ji 2001; Li and Ding 2004; Ding and Sikka 2006).

Overall, the above results reveal that the SCD is closely related to the large-scale circulation anomalies in both lower and mid-high latitudes in MJ. In the positive phase of the $\mathrm{SCD}$, the intensified WPSH and PSAC favor convergence (divergence) of water vapor in southeast (southwest) China, whereas the Eurasian wave-train pattern can lead to an enhanced East Asian subtropical front. These circulation conditions favor more rainfall anomalies in southeast China but less rainfall anomalies in southwest China. The converse is also true in the negative phase of the SCD.

\section{Oceanic drivers}

\subsection{SST anomalies associated with the South China Dipole}

SST anomalies play crucial roles in the variability of local rainfall and the associated large-scale atmospheric circulation. Figure 5 shows the SST anomalies regressed against the MJ SCD index during 1979-2014. Note that warm SST anomalies occur in the tropical central-eastern Pacific and cold SST anomalies in the northwest Pacific in the previous winter, which resembles the pattern of the El Niño mature phase. The correlation coefficient between the MJ SCD and the DJF Niño3.4 indices is 0.52 during 1979-2014, which is significant at the $99 \%$ confidence level. The El Niño-like 


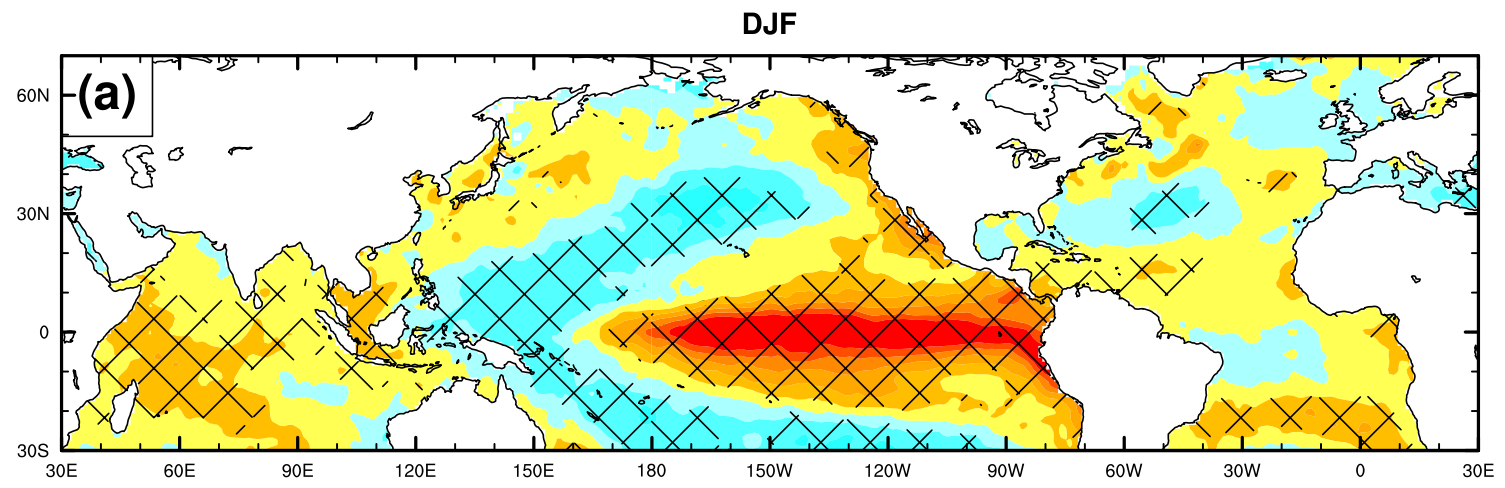

MA

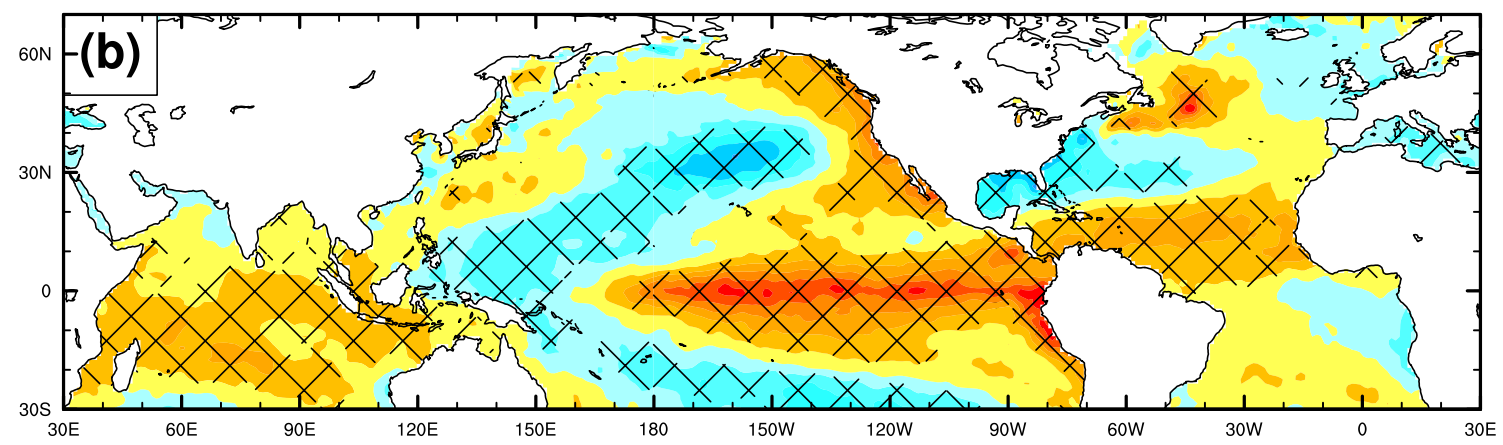

MJ
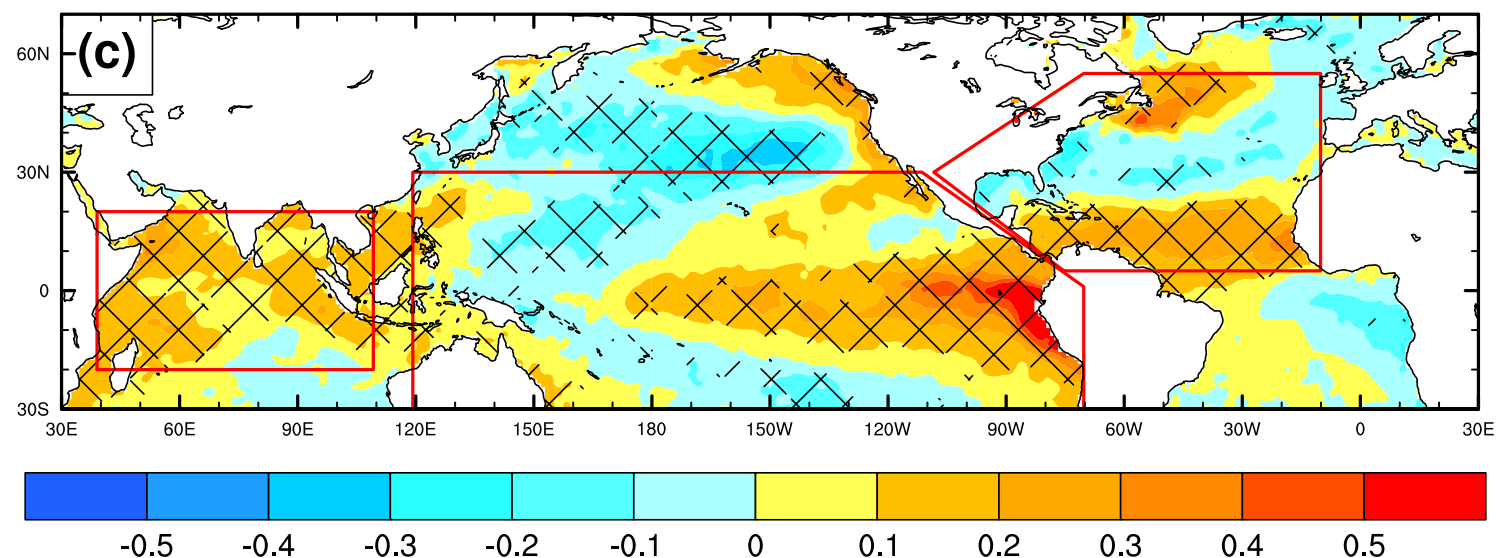

Fig. 5 Regressions of SST anomalies in DJF (a), MA (b), and MJ (c) against the MJ SCD index for the period 1979-2014. Areas exceeding the $95 \%$ confidence level are indicated by cross-hatching. The rec-

SST anomalies in the tropical Pacific weaken from the previous winter to early summer, suggesting that the SCD tends to occur in the early summer following the mature phase of ENSO.

Figure 5 clearly shows that in the positive phase of the MJ SCD, warm SST anomalies occur in the TIO and the South China Sea in the previous winter to early summer, resembling the positive Indian Ocean basin mode. This result is consistent with previous studies, which have demonstrated tangular boxes in the tropical Indian Ocean, tropical Pacific Ocean, and North Atlantic indicate the corresponding target regions for the numerical experiments

that the Indian Ocean basin usually warms up (cools down) following the El Niño (La Niña) peak, reaching a maximum during spring and persisting into early summer (Klein et al. 1999; Liu and Alexander 2007). The correlation coefficient between the MJ SCD and the MA (MJ) TIO indices is 0.46 (0.50) during 1979-2014, exceeding significance at the 99\% confidence level (Fig. 4b; Table 1). However, the correlation coefficient between the MJ SCD and the MA (MJ) TIO indices is only $0.07(0.22)$ after removing the ENSO 
Table 1 Correlations $(R)$ of the SCD, EU and PSAC indices in MJ (May-June) with the Niño3.4 index in winter (December-JanuaryFebruary, DJF), and the tropical Indian Ocean (TIO) SST index and the North Atlantic tripole (NAT) SST index in MA (March-April) and MJ during 1979-2014

\begin{tabular}{llll}
\hline & MJ SCD & MJ EU & MJ PSAC \\
\hline DJF Niño3.4 & $0.52^{\mathrm{b}}$ & 0.21 & $0.52^{\mathrm{b}}$ \\
MA TIO & $0.46^{\mathrm{b}}$ & 0.23 & $0.50^{\mathrm{b}}$ \\
MJ TIO & $0.50^{\mathrm{b}}$ & 0.25 & $0.49^{\mathrm{b}}$ \\
MA NAT & $0.51^{\mathrm{b}}$ & $0.43^{\mathrm{b}}$ & $0.59^{\mathrm{b}}$ \\
MJ NAT & $0.53^{\mathrm{b}}$ & $0.45^{\mathrm{b}}$ & $0.59^{\mathrm{b}}$ \\
MA TIO/DJF Niño3.4 & 0.07 & 0.13 & 0.25 \\
MJ TIO/DJF Niño3.4 & 0.22 & 0.16 & 0.19 \\
MA NAT/DJF Niño3.4 & $0.38^{\mathrm{a}}$ & $0.37^{\mathrm{a}}$ & $0.48^{\mathrm{b}}$ \\
MJ NAT/DJF Niño3.4 & $0.46^{\mathrm{b}}$ & $0.39^{\mathrm{a}}$ & $0.50^{\mathrm{b}}$ \\
\hline
\end{tabular}

The TIO (NAT) index, from which the impact of the previous DJF Niño3.4 index has been removed linearly, is shown as MA TIO/DJF Niño3.4 (MANAT/DJF Niño3.4)

a,b Denote the significance at 95 and $99 \%$ confidence levels, respectively

signal from these two indices, implying that the impact of the spring-summer TIO SST anomalies on the MJ SCD is closely related to the previous winter ENSO. This finding agrees with previous studies which reported that the TIO SST anomalies act as a capacitor linking ENSO and the East Asian summer climate (Yang et al. 2007; Xie et al. 2009).

Moreover, the SST anomalies associated with the MJ SCD index are characterized by a meridional tripole pattern in the North Atlantic, which intensifies from the previous winter to spring and early summer (Fig. 5). The correlation coefficient between the MJ SCD and the MA (MJ) NAT indices is 0.51 (0.53) during 1979-2014, and both are significant at the 99\% confidence level (Fig. 4b; Table 1). Previous studies have suggested that the North Atlantic tripole-like SST anomalies tend to occur during the ENSO-decaying spring and summer (Xie and Carton 2004; Wu et al. 2011). Though the MA NAT index is significantly correlated with the previous DJF Niño3.4 index $(R=0.42)$, the correlation coefficient between the MA (MJ) NAT and the MJ SCD indices still reaches $0.38(0.46)$ after removing the ENSO signal during 1979-2014, significant at the 95\% confidence level (Table 1). This indicates that the North Atlantic tripole-like SST anomalies in MA and MJ have a significant impact on the SCD in MJ, and that this is partially independent of the ENSO impact.

From the results presented above, the MJ SCD is closely related to SST anomalies in the tropical Pacific, the tropical Indian Ocean, and the North Atlantic in the previous winter to early summer, which resemble the pattern of the El Niño (La Niña) mature phase in the positive (negative) phase of the SCD. The impact of the TIO SST anomalies on the SCD is closely related to ENSO, whereas the impact of the North
Atlantic tripole-like SST anomalies only partially depends on ENSO. In fact, the North Atlantic tripole-like SST anomalies are also closely coupled with the North Atlantic Oscillation (NAO; Cayan 1992; Czaja and Frankignoul 2002; Zuo et al. 2013). As proposed in Chang et al. (2016), the tropical warm (cold) SST anomalies in the North Atlantic may result in a warming (cooling) in the northern Indian Ocean in summer. We find that the NAT index in MA has a correlation coefficient of $0.52(0.33)$ with the TIO index in MA (MJ) during 1979-2014, both exceeding significance at the $95 \%$ confidence level. This suggests that the TIO SST anomalies in MJ may be also related to the North Atlantic tripole-like SST anomalies in MA, but the associated physical mechanism still needs further examination, which is beyond the scope of present study.

\subsection{Impact of SST anomalies on the atmospheric circulation}

To further demonstrate the impact of SST anomalies on the MJ SCD and the associated large-scale atmospheric circulation anomalies, Fig. 6 presents the 500-hPa geopotential height and $850-\mathrm{hPa}$ stream function anomalies in $\mathrm{MJ}$ regressed against the previous DJF Niño3.4, MA TIO, and MA NAT indices during 1979-2014. A zonal wave-train pattern over the Eurasian continent and a low-level anomalous anticyclone in the northwest Pacific are clearly seen in all circulation anomaly fields associated with the SST index, despite some differences in the amplitude of the circulation anomalies (Fig. 6). These patterns of circulation anomalies resemble that associated with the MJ SCD index shown in Fig. 2b.

Moreover, the correlation coefficients of the PSAC index in MJ with the Niño3.4 index in DJF and the TIO and NAT in MA and MJ are all significant at the $99 \%$ confidence level during 1979-2014 (Table 1). This indicates that the MJ SCD-associated circulation anomalies over the middle-low latitudes are associated with SST anomalies in the tropical Pacific and Indian Ocean, and in the North Atlantic in the previous winter to early summer. However, the modified EU index in MJ, which is closely related to the SCD index in $\mathrm{MJ}$, is only significantly correlated with the NAT index in MA and MJ (Table 1), implying that the MJ SCD-related circulation anomalies over the Eurasian middle-high latitudes are likely associated with the North Atlantic tripole-like SST anomalies rather than the tropical Indo-Pacific SST anomalies in the previous winter to early summer.

We have shown that the basin-scale SST anomalies in the TIO and tripole-like SST anomalies in the North Atlantic are influenced in part by ENSO variability. Thus, we further examine the circulation anomalies in MJ regressed against the TIO and NAT indices in MA and MJ after linearly removing the previous winter ENSO signal. The high 
(a) MJ
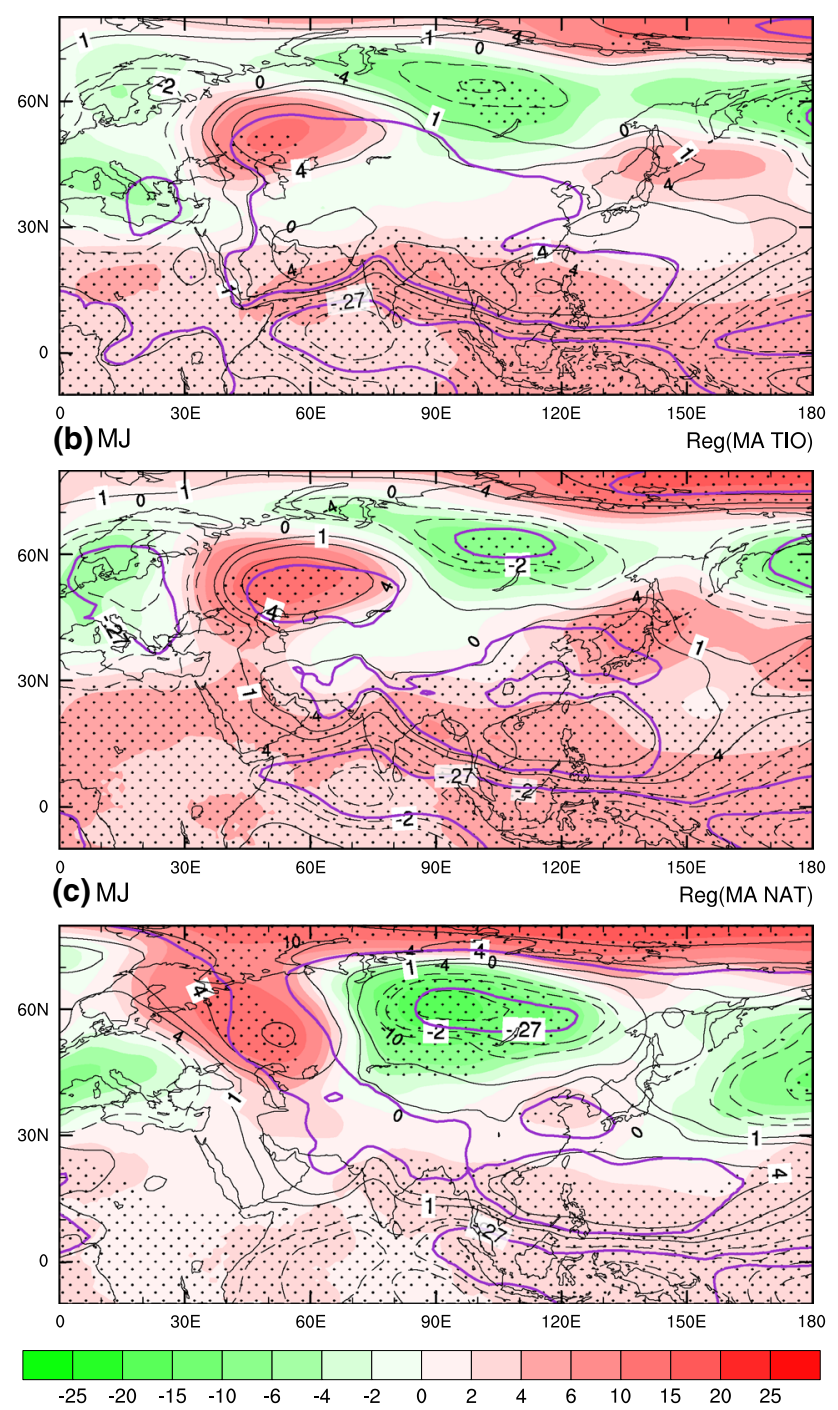

Fig. 6 Regressions of geopotential height (shading; gpm) anomalies at $500 \mathrm{hPa}$ and stream function (contours at $\pm 1, \pm 2, \pm 4, \pm 8$, and $\pm 16 \times 10^{5} \mathrm{~m}^{2} \mathrm{~s}^{-1}$; negative values are shown as dashed lines) anomalies at $850 \mathrm{hPa}$ in MJ against the a DJF Niño3.4 index, b MA TIO index, and c MA NAT index. Dots (purple contours) represent significance at the $90 \%$ confidence level for geopotential height (stream function) anomalies

correlation between the MA TIO and DJF Niño3.4 indices means that after removing the ENSO signal, the MJ geopotential height anomalies associated with the MA TIO index are weakened in the northwest Pacific and, in particular, the low-level anomalous anticyclone over the Philippine Sea almost vanishes (Fig. 7a). The correlation coefficients between the MA (MJ) TIO and MJ PSAC indices also decrease sharply and become insignificant after removing the ENSO signal. In contrast, the Eurasian wave-train pattern associated with the MA NAT index remains strong and significant after removing the ENSO signal (Fig. 7b). Though
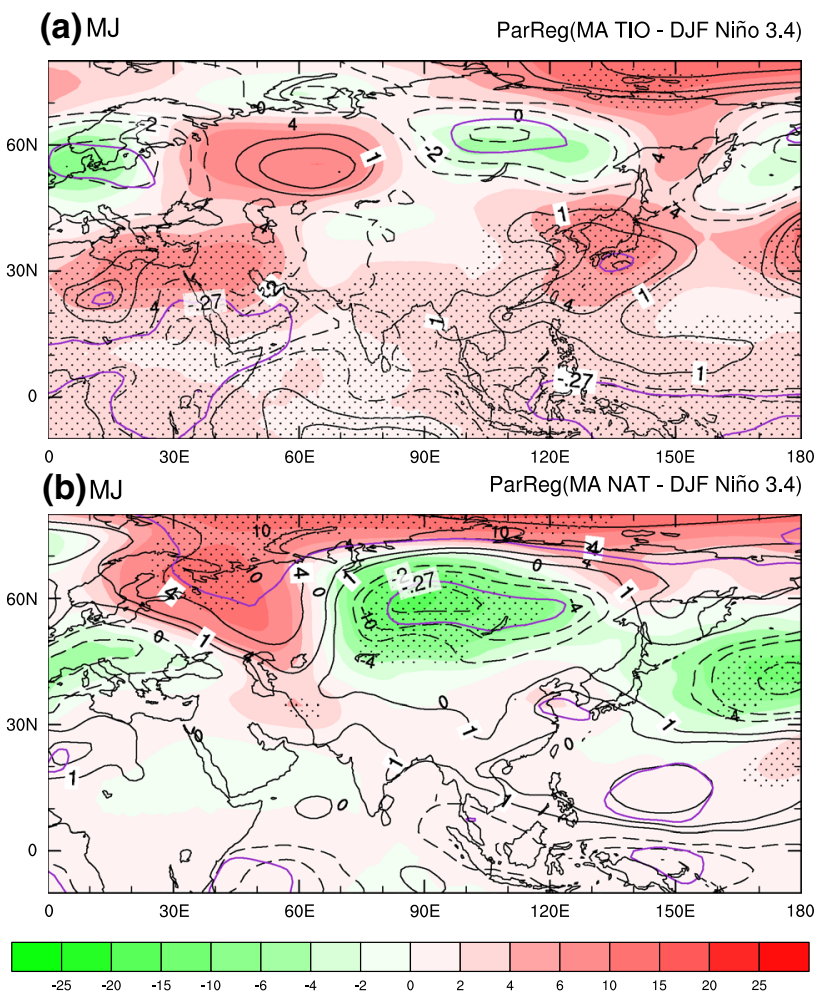

Fig. 7 Same as Fig. 6b, c, but for the regressions after removing the ENSO signal in the previous DJF season

the positive geopotential height anomalies in the northwest Pacific are much weaker at $500 \mathrm{hPa}$, anticyclonic circulation anomalies are still observed over a smaller region to the east of the Philippines at $850 \mathrm{hPa}$. This is consistent with the correlation coefficient between the MA (MJ) NAT and MJ PSAC indices remaining as high as $0.48(0.50)$ after removing the ENSO signal during 1979-2014 (Table 1).

From the above analysis, it can be concluded that the MJ SCD and associated circulation anomalies are closely related to SST anomalies in the tropical Pacific and Indian Ocean, and in the North Atlantic in the previous winter to early summer. The decaying ENSO-like SST anomalies in the tropical Pacific and Indian Ocean primarily affect the MJ SCD through changing the variability of the WPSH and PSAC, whereas the North Atlantic tripole-like SST anomalies mainly exert a downstream impact on the SCD by inducing a wave-train pattern over the Eurasian middle-high latitudes. The North Atlantic tripole-like SST anomalies also play a relatively weak role in modulating the PSAC variability.

\section{Simulations of the forcing mechanism by the CAM5 model}

Analysis of the observations has revealed the possible mechanisms responsible for the linkage between the early 
summer SCD and the previous winter-spring SST anomalies in the tropical Pacific, the tropical Indian Ocean, and the North Atlantic. To confirm the possible mechanisms and assess the contribution of SST anomalies in different ocean basins to the MJ SCD variability, we perform numerical experiments using the CAM5 model forced by SST anomalies regressed against the MJ SCD index. The spatial correlation of geopotential height at $850 \mathrm{hPa}$ between the control runs and observations is above 0.93, and is higher in the middle and upper troposphere. The root mean square errors are less than $0.5 \mathrm{gpm}$, and the ratios of standard deviation are between 0.88 and 1.09 , indicating that CAM5 is capable of reproducing realistic climatology and variations of geopotential height for a given climatological SST distribution. The CAM5 model can also capture the key features of the major seasonal variation of rainfall arising from the onset and advance of the Asian monsoon ( $\mathrm{Li}$ et al. 2015).

For the sensitivity experiments (TPO, TIO, NAT and PIA), the monthly SST anomalies are obtained by regression against the MJ SCD index during 1979-2014. The monthly SST anomalies are added to the climatological SSTs for the corresponding months. Target domains for these experiments are illustrated in Fig. 5c.

In the PIA runs, SST forcings from the tropical Pacific, the TIO, and the North Atlantic are all taken into consideration. The simulated geopotential height anomalies (Fig. 8a) are very close to those regressed against the SCD index in MJ (Fig. 2). In the northwest Pacific, there are significant positive geopotential height anomalies, indicating an enhancement and westward extension of the WPSH. The enhanced WPSH is concurrent with an intensified PSAC at $850 \mathrm{hPa}$. In addition, there is a wave train extending from the tropical northwest Pacific to the Okhotsk Sea, which resembles the East Asia-Pacific teleconnection pattern (EAP; Huang and Sun 1994). Also, there exists a wavetrain pattern accompanying wave activity flux (Takaya and Nakamura 2001) transport from the North Atlantic to the Eurasian mid-high latitudes, which resembles the observed EU-like pattern shown in Fig. 7b. Note that wave activity flux anomalies are transported from Europe to the Middle East and South Asia, concurrent with negative geopotential height anomalies over the Middle East and positive anomalies over and adjacent to north Indian. Therefore, the key (a) PIA minus Control

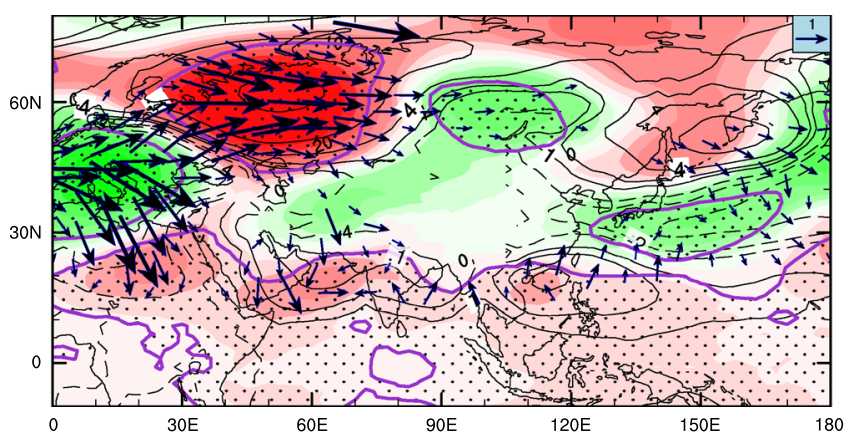

(c) TIO minus Control

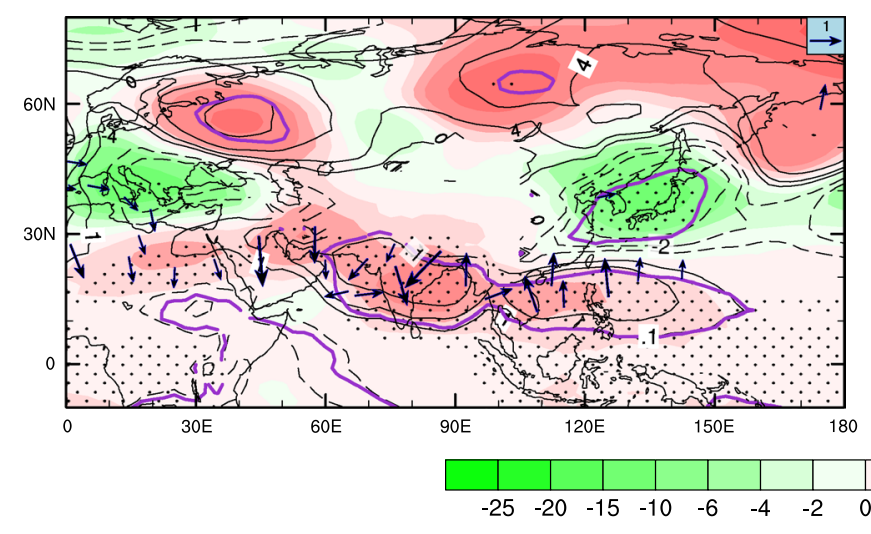

Fig. 8 a Differences in geopotential height (shading; gpm) and associated wave activity flux $\left(\mathrm{m}^{2} \mathrm{~s}^{-2}\right)$ at $500 \mathrm{hPa}$, and stream function anomalies (contours at $\pm 1, \pm 2, \pm 4, \pm 8$, and $\pm 16 \times 10^{5} \mathrm{~m}^{2} \mathrm{~s}^{-1}$; negative values are shown as dashed lines) at $850 \mathrm{hPa}$ in response to the a PIA, b TPO, c TIO, and d NAT SST forcing as obtained with (b) TPO minus Control

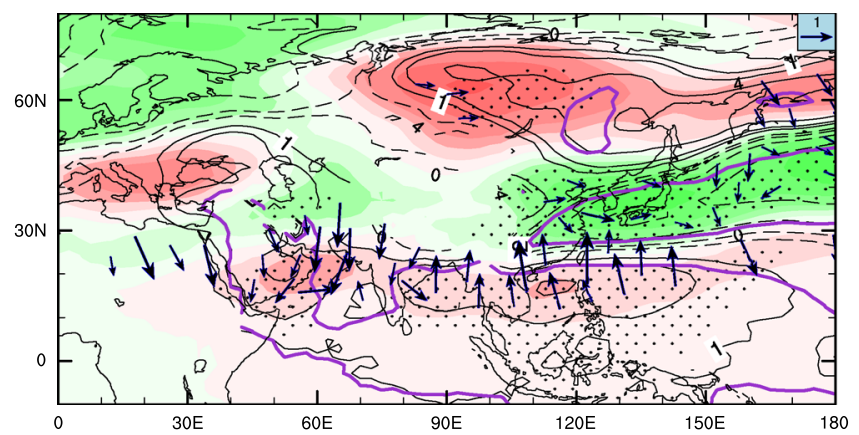

(d) NAT minus Control

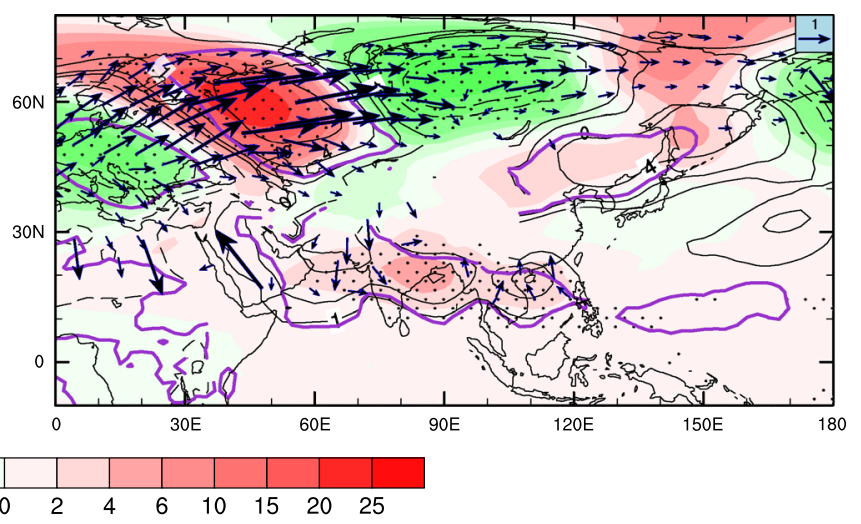

the CAM5 model. Dots represent significance at the $90 \%$ confidence level for geopotential height anomalies, and regions inside the purple contours indicate significance at the $90 \%$ confidence level for the stream function anomalies 
anomalous circulation systems associated with the MJ SCD are well captured in the PIA runs.

The EAP pattern is also well captured when only SST anomalies in the tropical Pacific or TIO are imposed as the boundary forcing (Fig. 8b, c), which is consistent with previous modeling studies (e.g. Wu et al. 2010; Kosaka et al. 2013). The simulated WPSH is intensified and extends westward, concurrent with an anomalous PSAC at $850 \mathrm{hPa}$ in MJ. Although an anomalous PSAC is clearly seen in both the TPO and TIO runs, the mechanisms responsible for its formation and maintenance are different. The basin-scale warming in the TIO can generate easterly wind anomalies extending into the western tropical Pacific by inducing an atmospheric Kelvin wave, and therefore leads to a low-level anomalous PSAC in the western Pacific (Xie et al. 2009, 2010). In contrast, the anomalous PSAC in the TPO runs is primarily excited and maintained by local cold SST anomalies in the tropical northwestern Pacific (Wang et al. 2000, 2003; Lau and Nath 2003; Xie and Carton 2004). The remote eastern-central Pacific warming also has a contribution to the PSAC variability (Zhang et al. 1996, 2017; Wang et al. 2000).

In the NAT runs (Fig. 8d), the atmospheric circulation response to the North Atlantic tripole-like SST forcing features a notable wave activity flux accompanying the wave train pattern from the North Atlantic to the Eurasian mid-high latitudes in MJ, which resembles the observed Eurasian wave-train pattern shown in Fig. 7b. This wave-train pattern is triggered primarily by diabatic heating associated with the tropical North Atlantic SST anomalies (shown in supplementary material: Fig. S1) and is enhanced by synoptic eddy-vorticity forcing related to the North Atlantic storm track activity (Zuo et al. 2013). Furthermore, an anomalous PSAC is observed over the western Pacificin the NAT runs, though its amplitude is much weaker than those in the TPO and TIO runs. This is in agreement with the observational data shown in Figs. 6 and 7. As noted in the previous studies (Ham et al. 2013; Hong et al. 2014; Chang et al. 2016), the impact of the North Atlantic SST anomalies on the PSAC is likely related to a westward atmospheric teleconnection. In the positive phase of the North Atlantic SST tripole, warm SST anomalies in the tropical North Atlantic favor an active convection over this region. (Figure not shown). This is concurrent with convergent (divergent) anomalies in the lower (upper) troposphere over the tropical Atlantic (Fig. 9a, b), as well as an anomalous low-level cyclone over the tropical North Atlantic and eastern Pacific (Fig. 9c), which resemble the Gill-type Rossby-wave response. Moreover, convergent (divergent) anomalies occur in the upper (lower) troposphere over the central Pacific, leading to suppressed convection and descending anomalies in the central Pacific and in turn producing an anomalous low-level anticyclone over the western Pacific.
Furthermore, comparison between Fig. 8a-c indicates that the atmospheric response is strong in East Asia and the northwest Pacific but relatively weak over the Eurasian mid-high latitudes in the TPO and TIO runs. In contrast, the atmospheric response is strong in the Eurasian mid-high latitudes but relatively weak in the northwest Pacific in the NAT run. This result is consistent with the observations, confirming that the Eurasian wave-train pattern is caused primarily by tripole-like SST anomalies in the North Atlantic, and the anomalous PSAC is related mainly to SST anomalies in the tropical Pacific and Indian Ocean. Moreover, a dipole pattern with increased (decreased) rainfall anomalies over southeast (southwest) China in MJ is captured well in all four sensitivity experiments (Fig. 10). In particularly, the PIA run has a high skill in simulating the SCD mode, with the spatial correlation coefficient reaches about 0.8 . Also, the dipole pattern in the model runs resembles that regressed against the SST index (shown in supplementary material: Fig. S2). Consistency between model simulations and observations further supports the important role of SST anomalies in inducing the SCD in early summer.

Therefore, the resemblance between the simulations and observations confirms the impact of SST anomalies in the tropical Pacific and Indian oceans and the North Atlantic on atmospheric circulation over Eurasia and the western Pacific that links directly to the MJ SCD variability. The North Atlantic tripole-like SST anomalies appear to play a more important role in inducing the EU-like pattern over Eurasian mid-high latitudes, whereas the tropical Pacific and Indian Ocean SST anomalies tend to contribute more to the variations of the WPSH and PSAC. Based on the results found herein and related findings from the previous studies, Fig. 11 shows a schematic diagram of the mechanisms responsible for the linkage between the SCD in early summer and SST anomalies in the previous winter to early summer.

\section{Summary and discussion}

The leading mode of rainfall variability in southern China and the associated changes in atmospheric circulation in early summer (May-Jun) were analyzed. The results show that during 1979-2014 the first leading mode of southern China rainfall anomalies features a zonal dipole pattern (SCD) in early summer. The positive phase of the SCD is characterized by increased (decreased) rainfall anomalies in southeast (southwest) China, and vice versa in the negative phase. When the SCD is in its positive phase, the WPSH tends to be intensified and shifted westward, concurrent with an anomalous PSAC in the lower troposphere. The intensified WPSH and PSAC favor the convergence (divergence) of water vapor over southeast (southwest) China, leading to increased (decreased) rainfall over this region. Moreover, 
Fig. 9 Differences in velocity potential (unit: $10^{-6} \mathrm{~m}^{2} \mathrm{~s}^{-1}$ ) at a $850 \mathrm{hPa}$ and b $200 \mathrm{hPa}$ and c stream function (shading; unit: $10^{5} \mathrm{~m}^{2} \mathrm{~s}^{-1}$ ) and wind (vector; $\mathrm{m} \mathrm{s}^{-1}$ ) at $850 \mathrm{hPa}$ in $\mathrm{MJ}$ in response to the NAT SST forcing as obtained with the CAM5 model. Dots represent stream function anomalies that are significant at the $90 \%$ confidence level
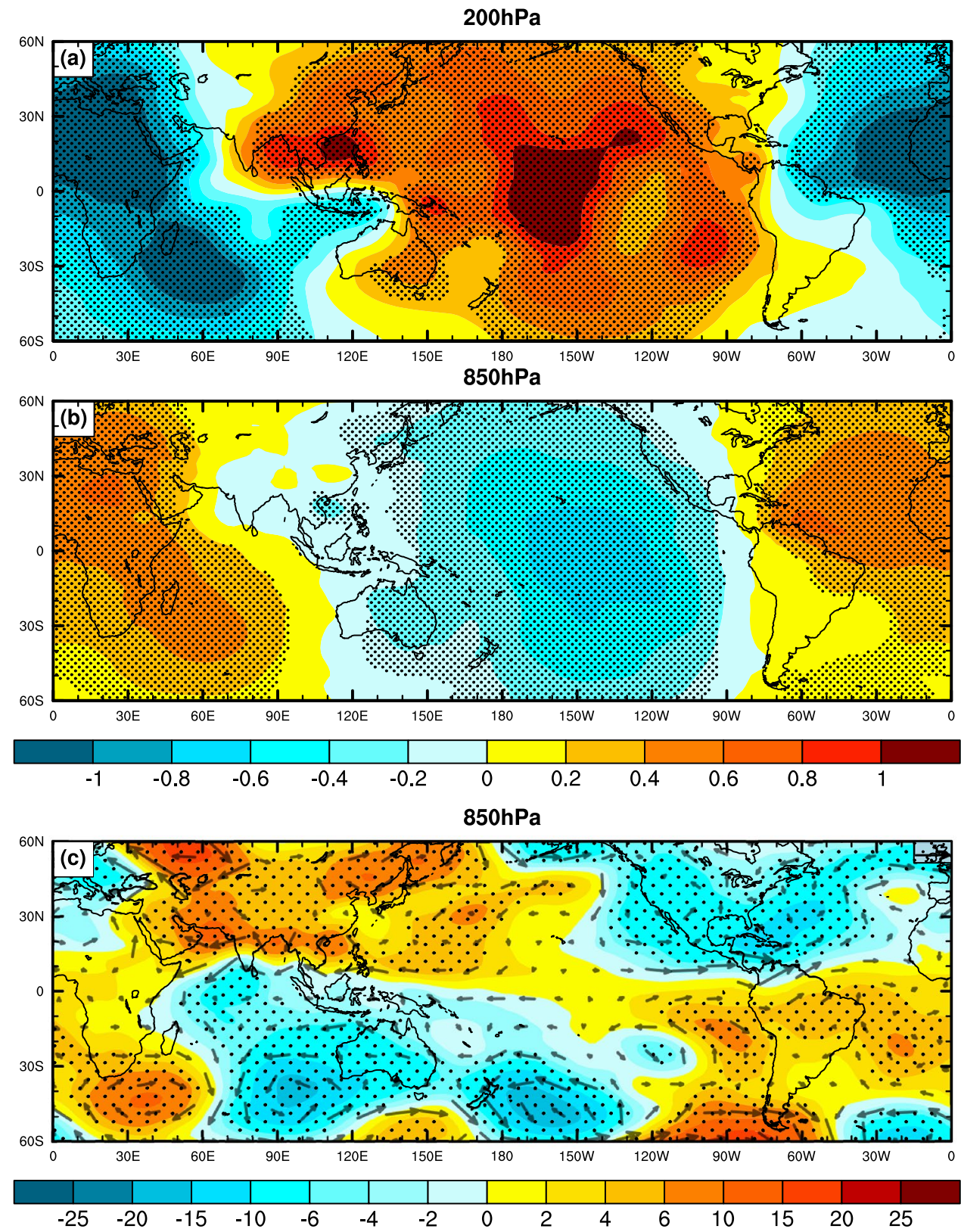

there are low-level easterly wind anomalies over north India, which reduce the transport of water vapor from the tropical ocean to southwest China and thus lead to less rainfall over this region. Additionally, a wave-train pattern with positive geopotential height anomalies over the Ural Mountains is clearly observed in the mid-high latitudes of Eurasia. Such a pattern favors an enhancement of the East Asian subtropical front, and thus leads to increased (decreased) rainfall anomalies in southeast (southwest) China (Zhang and Tao 1998; Li and Ji 2001; Li and Ding 2004; Ding and Sikka 2006).

We found that the early summer SCD and associated atmospheric circulation anomalies are closely related to decaying ENSO-like SST anomalies in the tropical IndoPacific Ocean and tripole-like SST anomalies in the North
Atlantic in the previous winter to early summer. When the SCD is in its positive phase in early summer, warm (cold) SST anomalies are observed in the tropical central-eastern Pacific and Indian Ocean (western Pacific) in the previous winter to early summer, and vice versa for the negative phase. Correlations between the SCD in early summer and SST anomalies in the previous winter to early summer show a tripole pattern in the North Atlantic, with positive correlations in the tropical and subpolar ocean, and negative correlations in the northwestern North Atlantic. The SCD-related SST anomalies in the tropical central-eastern Pacific are stronger in winter than in spring and early summer, whereas the SCD-associated SST anomalies in the TIO and the North Atlantic are most significant in 

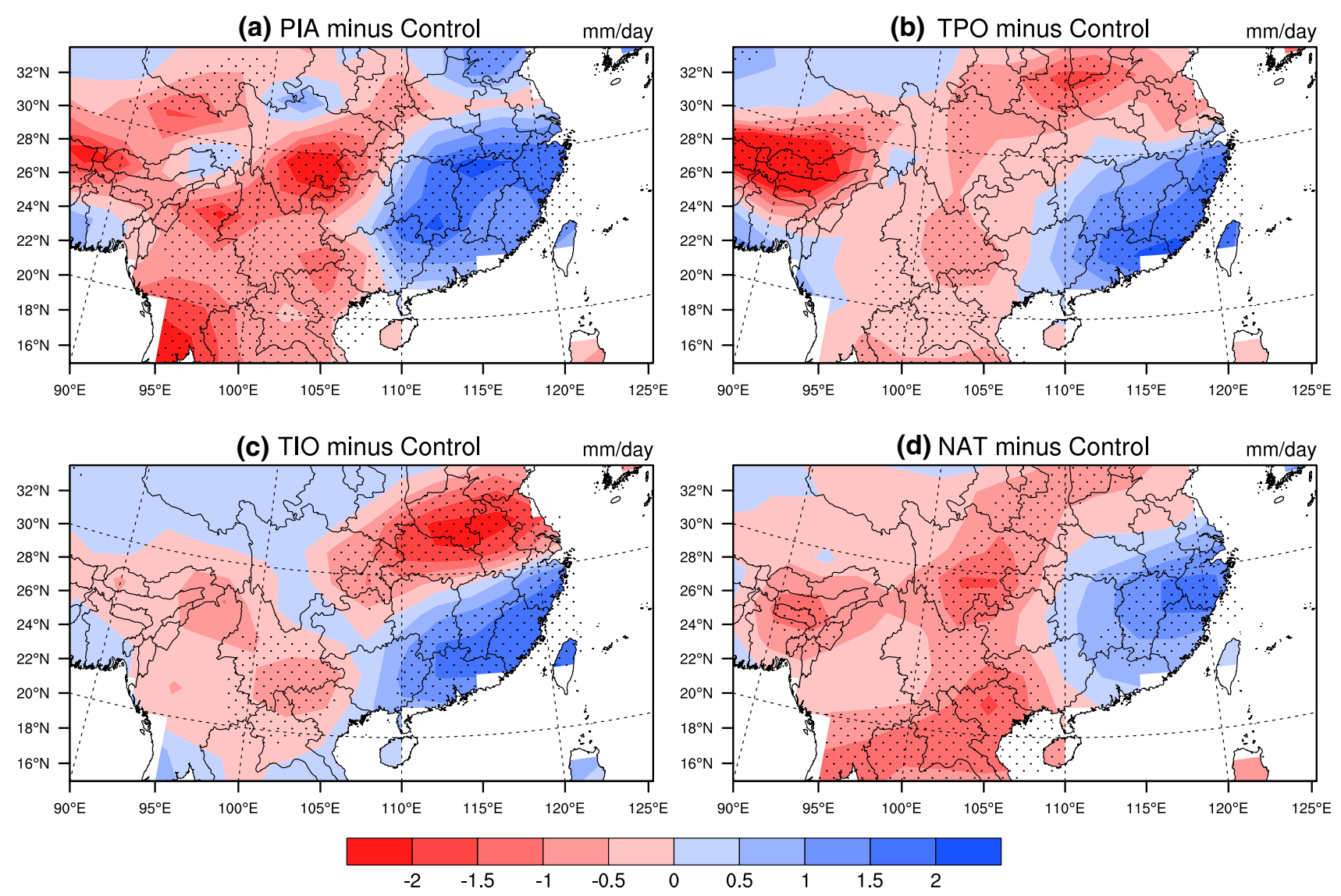

Fig. 10 Same as Fig. 8, but for rainfall anomalies $\left(\mathrm{mm} \mathrm{day}^{-1}\right)$. Dots denote significance at the $90 \%$ confidence level

Fig. 11 Schematic summarizing the possible mechanisms responsible for the linkage between the early summer SCD and SST anomalies in the previous winter to early summer

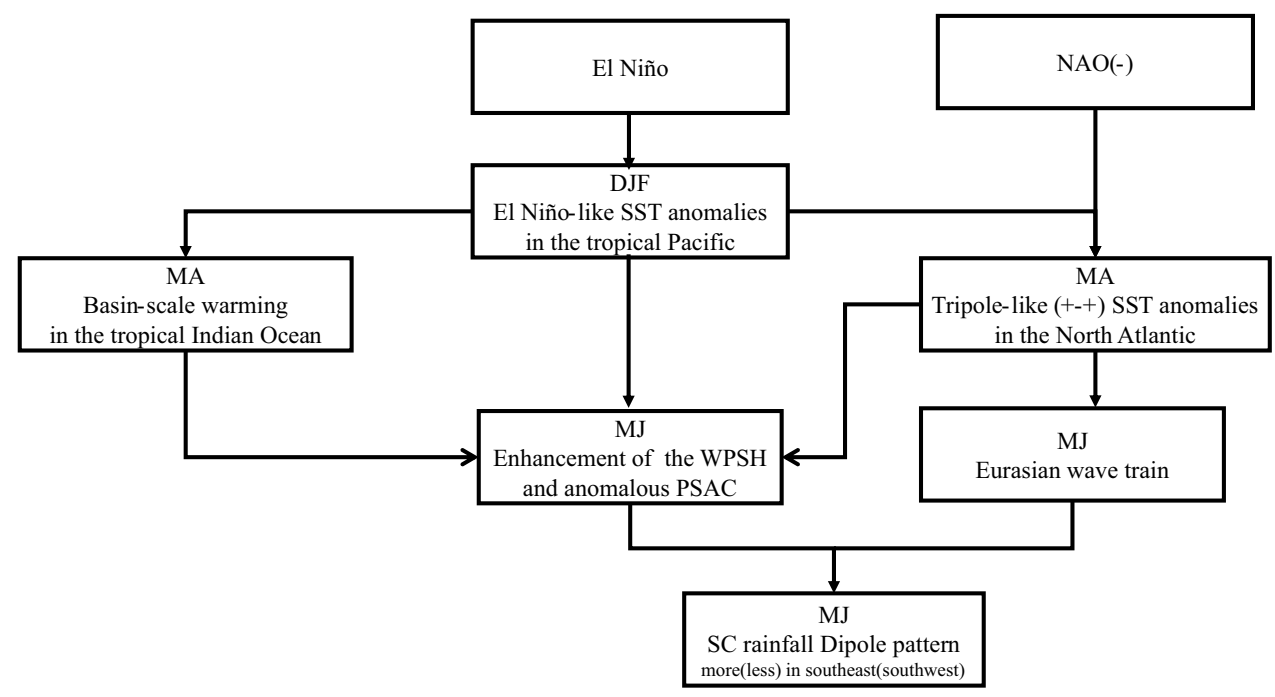

spring and early summer. The spring-summer SST anomalies in the TIO are closely related to the previous winter ENSO, indicating that the TIO acts as a capacitor linking the winter ENSO to the following early summer SCD (Yang et al. 2007; Xie et al. 2009). Although the North
Atlantic tripole-like SST anomalies in spring and summer are partly related to the previous winter ENSO, their relationship with the SCD in early summer is still statistically significant after removing the ENSO signal. This is reasonable, given that the North Atlantic tripole-like SST 
anomalies are also closely coupled with the NAO (Cayan 1992; Czaja and Frankignoul 2002; Zuo et al. 2013).

The physical mechanisms that establish the linkage between the SCD in early summer and SST anomalies in the previous winter to early summer were further explored by analyzing observations and a set of numerical experiments run on the CAM5 model. The decaying El Niño (La Niña)-like SST anomalies in the tropical Pacific that peak in winter primarily exert an impact on the following early summer SCD by inducing an anomalous low-level anticyclone (cyclone) over the Philippine Sea. The formation and maintenance of the PSAC are attributed to both in situ and remote eastern-central Pacific SST anomalies through an atmospheric Rossby wave response and wind-evaporation feedback (Wang et al. 2000; Zhang et al. 2017). In addition, warm (cold) SST anomalies are observed in the TIO in the spring following an El Niño (La Niña) peak, which can persist into early summer and thus generate easterly wind anomalies extending into the western equatorial Pacific (Xie et al. 2009, 2010). Therefore, the basin-scale SST anomalies in the TIO can give rise to and prolong the anomalous PSAC, leading to changes in the SCD in early summer.

Observational and numerical results suggest that the tripole-like SST anomalies in the North Atlantic can persist from spring to early summer and exert a downstream impact on the SCD by inducing a Eurasian wave-train pattern. Such a pattern is triggered primarily by diabatic heating associated with the tropical North Atlantic SST anomalies and is enhanced by synoptic eddy-vorticity forcing related to North Atlantic storm track activity (Zuo et al. 2013). In addition, the North Atlantic tripole-like SST anomalies in spring have a delayed impact on the variability of the PSAC and SCD in early summer through a westward atmospheric teleconnection (Hong et al. 2014; Chang et al. 2016), though this effect is weaker than that of SST anomalies in the tropical Pacific and Indian Ocean.

Moreover, the SCD in early summer is well captured in the sensitivity experiment with SST forcing in different ocean basins. It is important to note that the patterns of the response of atmospheric circulation and southern China rainfall anomalies to SST anomalies in all three ocean basins bear most similarity to the observations in early summer. In other words, the combined effect of SST anomalies has more effect on the SCD and associated circulation anomalies than the individual effect of SST anomalies in any single oceanic basin.

This work mainly focused on the impact of SST anomalies in winter and spring on the following early summer SCD and associated circulation anomalies. However, other factors, such as Arctic sea ice (e.g., Zhao et al. 2004; Wu et al. 2009a) and snow anomalies in the Eurasia and the Tibetan Plateau (e.g., Wu and Qian 2003; Wu et al. 2009b; Ren et al. 2016), could also influence early summer southern China rainfall anomalies, but these factors are outside the scope of this work.

Acknowledgements The authors are indebted to Dr. Peili Wu of the Hadley Centre for Climate Prediction and Research for carefully reading and helpful comments on the original manuscript. This research was jointly supported by the National Basic Research Program of China (Grant 2013CB430203), the China Meteorological Special Programs (Grants GYHY201506013), the National Key Research and Development Program of China (during the 13th Five-year Plan) (Grants 2016YFA0601501). The authors are grateful to two anonymous reviewers for their insightful comments to improve the quality of the paper.

Open Access This article is distributed under the terms of the Creative Commons Attribution 4.0 International License (http://creativecommons.org/licenses/by/4.0/), which permits unrestricted use, distribution, and reproduction in any medium, provided you give appropriate credit to the original author(s) and the source, provide a link to the Creative Commons license, and indicate if changes were made.

\section{References}

Cayan DR (1992) Latent and sensible heat flux anomalies over the northern oceans: driving the sea surface temperature. J Phys Oceanogr 22(8):859-881. doi:10.1175/1520-0485(1992)022<0859:LASH $\mathrm{FA}>2.0 . \mathrm{CO} ; 2$

Chang CP, Zhang Y, Li T (2000) Interannual and interdecadal variations of the East Asian Summer Monsoon and tropical Pacific SSTs. Part I: roles of the subtropical ridge. J Clim 13:4310-4325. doi:10.1175/1520-0442(2000)013<4310:IAIVOT>2.0.CO;2

Chang TC, Hsu HH, Hong CC (2016) Enhanced influences of tropical Atlantic SST on WNP-NIO atmosphere-ocean coupling since the Early 1980s. J Clim 29:6509-6525. doi:10.1175/ JCLI-D-15-0807.1

Chen LX, Li W, Zhao P, Tao SY (2001) On the process of summer monsoon onset over East Asia. J Meteorol Res 15:436-449

Czaja A, Frankignoul C (2002) Observed impact of Atlantic SST anomalies on the North Atlantic oscillation. J Clim 15:606-623. doi: 10.1175/1520-0442(2002)015<0606:OIOASA > 2.0.CO;2

Dee DP et al (2011) The ERA-Interim reanalysis: configuration and performance of the data assimilation system. Q J Roy Meteorol Soc 137:553-597. doi:10.1002/qj.828

Ding YH, Chan JCL (2005) The East Asian summer monsoon: an overview. Meteorol Atmos Phys 89:117-142. doi:10.1007/ s00703-005-0125-z

Ding YH, Sikka DR (2006) Synoptic systems and weather. In: Wang B (ed) The Asian monsoon, vol 201. Springer, New York, p 131

Ham YG, Kug JS, Park JY, Jin FF (2013) Sea surface temperature in the north tropical Atlantic as a trigger for El Niño/Southern Oscillation events. Nat Geosci 6:112-116. doi:10.1038/NEGO1686

Hong CC, Chang TC, Hsu HH (2014) Enhanced relationship between the tropical Atlantic SST and the summertime western North Pacific subtropical high after the early 1980s. J Geophys Res Atmos 119:3715-3722. doi:10.1002/2013JD021394

Huang RH, Sun FY (1994) The impact of thermal state in the western Pacific warm pool and the convective activity above the warm pool on the east Asian climate anomalies (in Chinese). Chin J Atmos Sci 18:141-151

Klein SA, Soden BJ, Lau NC (1999) Remote sea surface temperature variations during ENSO: evidence for a tropical atmospheric bridge. J Clim 12:917-932. doi:10.1175/1520-0442(1999)012<0917:RSSTVD>2.0.CO;2 
Kosaka Y, Xie SP, Lau NC, Vecchi GA (2013) Origin of seasonal predictability for summer climate over the Northwestern Pacific. Proc Natl Acad Sci USA 110:7574-7579. doi:10.1073/ pnas. 1215582110

Lau KM (1992) East Asian summer monsoon rainfall variability and climate teleconnection. J Meteorol Soc Jpn 70:211-242

Lau NC, Nath MJ (2003) Atmosphere-ocean variations in the Indo-Pacific sector during ENSO episodes. J Clim 16:3-20. doi:10.1175/1520-0442(2003)016<0003:AOVITI > 2.0.CO;2

Lee $\mathrm{MH}$, Ho CH, Kim JH(2010) Influence of tropical cyclone landfalls on spatiotemporal variations in typhoon season rainfall over South China. Adv Atmos Sci 27:443-454. doi:10.1007/ s00376-009-9106-3

Li F, Ding YH (2004) A statistical study of blocking highs in Eurasia in summer by using 30-year NCEP datasets (in Chinese). Acta Meteorol Sin 62:347-354

Li S, Ji L((2001) Background circulation characteristics of the persistent anomalies of the summertime circulation over the Ural Mountains (in Chinese). Acta Meteorol Sin (in Chinese) 59:280-293

Li J, Yu R, Yuan W, Chen H, Sun W, Zhang Y (2015) Precipitation over East Asia simulated by NCAR CAM5 at different horizontal resolutions. J Adv Model Earth Syst 7:774-790. doi:10.1002/20 14MS000414

Liu Z, Alexander M (2007) Atmospheric bridge, oceanictunnel, and global climatic teleconnections. Rev Geophys. doi:10.1029/200 5RG000172

Liu Y, Li W, Ai W, Li Q (2012) Reconstruction and application of the monthly western Pacific subtropical high indices. J Appl Meteor 23:414-423 (in Chinese)

Mao JY, Chan JCL, Wu GX (2011) Interannual variations of early summer monsoon rainfall over South China under different PDO backgrounds. Int J Climatol 31:847-862. doi:10.1002/joc.2129

North GR, Bell TL, Cahalan RF, Moeng FJ (1982) Sampling errors in the estimation of empirical orthogonal functions. Mon Weather Rev 110:699-706

Rayner NA, Parker DE, Horton EB, Folland CK, Alexander LV, Rowell DP, Kent EC, Kaplan A (2003) Global analyses of sea surface temperature, sea ice, and night marine air temperature since the late nineteenth century. J Geophys Res 108:4407. doi:10.1029/2 002JD002670

Ren FM, Gleason B, Easterling D(2002) Typhoon impacts on China's precipitation during 1957-1996. Adv Atmos Sci 19:943-952. doi:10.1007/s00376-002-0057-1

Ren HC, Li W, Ren HL, Zuo J((2016) Distinct linkage between winter Tibetan Plateau snow depth and early summer Philippine Sea anomalous anticyclone. Atmos Sci Lett 17:223-229. doi:10.1002/ asl.646

Simmonds I, Bi D, Hope P (1999) Atmospheric water vapor flux and its association with rainfall over China in summer. J Clim 12:1353-1367. doi:10.1175/1520-0442(1999)012<1353:AWVF $\mathrm{AI}>2.0 . \mathrm{CO} ; 2$

Su Q, Lu R, Li C(2014) Large-scale circulation anomalies associated with interannual variation in monthly rainfall over South China from May to August. Adv Atmos Sci 31:273-282. doi:10.1007/ s00376-013-3051-x

Takaya K, Nakamura H (2001) A formulation of a phase-independent wave-activity flux for stationary and migratory quasigeostrophic eddies on a zonally varying basic flow. J Atmos Sci 58:608-627. doi:10.1175/1520-0469(2001)058<0608:AFOAPI > 2.0.CO;2

Wallace JM, Gutzler DS (1981) Teleconnections in the geopotential height field during the Northern Hemisphere winter. Mon Weather Rev 109:784-812. doi:10.1175/1520-0493(1981)109<0784:TIT $\mathrm{GHF}>2.0 . \mathrm{CO} ; 2$

Wang B, Wu R, Fu X (2000) Pacific-East Asia teleconnection: how does ENSO affect East Asian climate? J Clim 13:1517-1536. doi:10.1175/1520-0442(2000)013<1517:PEATHD>2.0.CO;2
Wang B, Wu R, Li T (2003) Atmosphere-warm ocean interaction and its impact on Asian-Australian monsoon variability. J Clim 16:1195-1211. doi:10.1175/1520-0442(2003)16<1195:AOIAII $>2.0 . \mathrm{CO} ; 2$

Wang B, Liu J, Yang J, Zhou T, Wu Z (2009) Distinct principal modes of early and late summer rainfall anomalies in East Asia. J Clim 22:3864-3875. doi:10.1175/2009JCLI2850.1

Wu TW, Qian ZA (2003) The relation between the Tibetan winter snow and the Asian summer monsoon and rainfall: an observational investigation. J Clim 16:2038-2051. doi:10.1175/1520-0442(2003)016<2038:TRBTTW>2.0.CO;2

Wu B, Zhang R, Wang B, D'Arrigo R (2009a) On the association between spring Arctic sea ice concentration and Chinese summer rainfall. Geophys Res Lett. doi:10.1029/2009GL037299

Wu B, Yang K, Zhang R (2009b) Eurasian snow cover variability and its association with summer rainfall in China. Adv Atmos Sci 26:31-44.doi:10.1007/s00376-009-0031-2

Wu B, Li T, Zhou T (2010) Relative contributions of the Indian Ocean and local SST anomalies to the maintenance of the western north Pacific anomalous anticyclone during the El Niño Decaying Summer. J Clim 23:2974-2986. doi:10.1175/2010JCLI3300.1

Wu R, Yang S, Liu S, Lian Y, Gao Z(2011) Northeast China summer temperature and North Atlantic SST. J Geophys Res. doi:10.102 9/2011JD015779

Xie SP, Carton JA(2004) Tropical Atlantic variability: patterns, mechanisms, and impacts. Earth climate: the ocean-atmosphere interaction. Geophys Monogr. doi:10.1029/147GM07

Xie SP, Hu K, Hafner J, Tokinaga H, Du Y, Huang G, Sampe T (2009) Indian Ocean capacitor effect on Indo-western Pacific climate during the summer following El Niño. J Clim 22:730-747. doi:10.1 175/2008JCLI2544.1

Xie SP, Du Y, Huang G, Zheng XT, Tokinaga H, Hu KM, Liu QY (2010) Decadal shift in El Niño influences on Indo-Western Pacific and East Asian climate in the 1970s. J Clim 23:3352-3368. doi:10.1175/2010JCLI3429.1

Yang J, Liu Q, Xie SP, Liu Z, Wu L (2007) Impact of the Indian Ocean SST basin mode on the Asian summer monsoon. Geophys Res Lett 34:L02708. doi:10.1029/2006GL028571

Ye H, Lu R (2011) Subseasonal variation in ENSO-related East Asian rainfall anomalies during summer and its role in weakening the relationship between the ENSO and summer rainfall in eastern China since the late 1970s. J Clim 24:2271-2284. doi:10.1175/ 2010JCLI3747.1

Yim SY, Wang B, Xing W (2014) Prediction of early summer rainfall over South China by a physical-empirical model. Clim Dyn 43:1883-1891. doi:10.1007/s00382-013-2014-3

Zhang RH(2001) Relations of water vapor transport from Indian monsoon with that over east Asia and the summer rainfall in China. Adv Atmos Sci 18:1005-1017

Zhang QY, Tao SY (1998) Influence of Asian mid-high latitude circulation on East Asian summer rainfall. Acta Meteorol Sin (in Chinese) 56:199-211

Zhang RH, Sumi A, Kimoto M (1996) Impact of El Niño on the East Asian Monsoon: a diagnostic study of the '86/87 and '91/92 events. J Meteor Soc Japan 74:49-62. doi:10.2151/ jmsj1965.74.1_49

Zhang RH, Min QY, Su JZ (2017) Impact of El Niño on atmospheric circulations over East Asia and rainfall in China: role of the anomalous western North Pacific anticyclone. J Sci China Earth Sci. doi:10.1007/s11430-016-9026-x

Zhao P, Zhang X, Zhou X, Ikeda M, Yin Y (2004) The sea ice extent anomaly in the North Pacific and its impact on the East Asian summer monsoon rainfall. J Clim 17:3434-3447. doi:10.1175/1520-0442(2004)017<3434:TSIEAI > 2.0.CO;2

Zheng B, Liang JY, Lin AL, Li CH, Gu DJ (2006) Frontal rain and summer monsoon rain during pre-rainy season in South China. 
Part I: determination of the division dates. Chin J Atmos Sci (in Chinese) 30:1207-1216

Zhou TJ, Yu RC (2005) Atmospheric water vapor transport associated with typical anomalous summer rainfall patterns in China. J Geophys Res. doi:10.1029/2004JD005413
Zuo JQ, Li WJ, Sun CH, Xu L, Ren HL (2013) Impact of the North Atlantic sea surface temperature tripole on the East Asian summer monsoon. Adv Atmos Sci 30:1173-1186. doi:10.1007/ s00376-012-2125-5 